\title{
Protective Effect of Dietary Curcumin and Capsaicin on LPS-Induced Inflammation in Mice
}

\author{
Thriveni Vasanthkumar', Manjunatha Hanumanthappa ${ }^{1 *}$, Prabhakar BT $^{2}$
}

\section{Thriveni Vasanthkumar ${ }^{1}$, Manjunatha Hanumanthappa ${ }^{1 *}$, Prabhakar $\mathrm{BT}^{2}$}

${ }^{1}$ Department of PG Studies and Research in Biotechnology, Kuvempu University, Shankaraghatta, Shimoga, Karnataka, INDIA.

${ }^{2}$ Molecular Biomedicine Laboratory, Postgraduate Department of Studies and Research in Biotechnology, Sahyadri Science College, Kuvempu University, Shimoga, Karnataka, INDIA.

\section{Correspondence}

Manjunatha $\mathbf{H}$

Assistant professor, Department of Biotechnology, Jnana Sahyadri, Kuvempu University, Shankaraghatta - 577 451, Shimoga, Karnataka, INDIA.

Phone no: +91 8762661348

E-mail: manjunatha75@gmail.com

History

- Submission Date: 22-02-2018,

- Review Date: 05-04-2018;

- Accepted Date: 05-04-2018

DOI : 10.5530/pj.2018.4.121

Article Available online http://www.phcogj.com/v10/i4

\section{Copyright}

(C) 2018 Phcog.Net. This is an openaccess article distributed under the terms of the Creative Commons Attribution 4.0 International license.

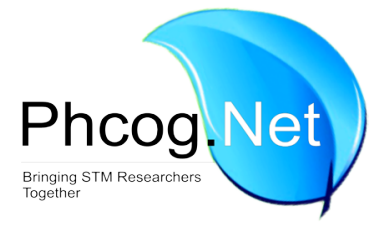

\begin{abstract}
Objective: The current study aimed to evaluate the anti-inflammatory potency of combined curcumin and capsaicin against lipopolysaccharide (LPS) induced organ damage in mice. Methods: Adult male albino mice were distributed into five experimental groups for treatment with olive oil, LPS, curcumin, capsaicin and their combination, respectively, for 7 days prior to LPS induced inflammation. At the end of the experiment, blood samples were collected and used for the analysis of serum non-specific enzymes including serum glutamate oxaloacetate transaminase (SGOT), serum glutamate pyruvate transaminase (SGPT), alkaline phosphatase (ALP), total bilirubin (TB), urea, creatinine and sugar, while the organ homogenates were subjected for the evaluation of antioxidant enzymes such as superoxide dismutase (SOD), catalase (CAT), glutothione $\mathrm{S}$ transferase (GST), nitric oxide (NO); lipid peroxidation (LPO) and it was further confirmed by histopathological study of different organs. Results and Conclusion: Curcumin, capsaicin and their combination had shown significant restoration of non-specific serum enzymes, antioxidant enzymes and attenuated inflammatory cells infiltration thereby preventing tissue/organ damage in LPS-challenged mice. However, the protective effect was found to be more when the two compounds were fed in combination. This beneficial potency of combined spice treatment is may be due to the contribution of diversified active moieties of curcumin and capsaicin in combination compared to individual molecules. Key words: Curcumin, Capsaicin, LPS, Septic shock, Lipid peroxidation, Superoxide dismutase.
\end{abstract}

\section{INTRODUCTION}

Sepsis is a systemic inflammatory response to infection mediated through cytokines and free radicals for controlling local inflammation with eventual elimination of invading pathogens. ${ }^{1,2}$ Massive and uncontrolled release of cytokines such as tumor necrosis factor-alpha (TNF- $\alpha$ ), interleukin-1 $\beta$ (IL-1 $\beta$ ), high mobility group box-1 (HMGB1) 3$)^{3,4}$ and free radicals trigger the systemic inflammatory process. These mediators contribute to the migration of leukocytes, lymphocytes, and platelets to the infected area and cause endothelial damage, increased microvascular permeability, vasoplegia, hypoperfusion, ischemia/reperfusion injury leading to organ dysfunction and death. 5,6

LPS, the outer membrane component of Gram-negative bacteria, is a major pathogenic factor in sepsis ${ }^{7}$ and is a widely used valuable and reproducible model to induce systemic inflammatory response in laboratory animals, which mimic the initial clinical features of sepsis. ${ }^{8}$ Development of significant therapeutic strategies have been made to treat sepsis, nevertheless mortality rate was not significantly decreased. ${ }^{9}$ Previous studies have reported that antioxidants are able to protect LPS-induced septic shock in vivo.

Curcumin, a polyphenol of Curcuma longa, reported for its beneficial anti-inflammatory, antioxidant, antimutagenic and anticancer activities. ${ }^{10-12}$ Effective in protecting heat induced oxidant stress, ${ }^{13}$ chromiuminduced renal damage,$^{14}$ cisplatin-induced hepatotoxicity, ${ }^{15}$ aluminum-induced mitochondrial dysfunction in vivo. ${ }^{16}$ Whereas, capsaicin, a component of Capsicum annum exerts various pharmacological properties, including antioxidant, anti-inflammatory and anti-epileptic effects. ${ }^{17,18,19}$ In vivo reports have established that capsaicin inhibits cisplatininduced nephrotoxicity, Lipid peroxidation, renal injury, oxidative stress and inflammation, ${ }^{20,21}$ cecal ligation and puncture (CLP) induced systemic inflammatory responses. ${ }^{22}$ Mechanism of action of curcumin and capsaicin on health beneficial activity have been extensively studied and reported..$^{23,24,25}$ Although these two spice principles share a considerable amount of structural homology nevertheless possesses notable differences in the mechanism of action. The present study was designed to evaluate protective effect of combined curcumin and capsaicin against LPS-induced inflammation in mice.

\section{MATERIALS AND METHODS}

\section{Chemicals}

Curcumin, capsaicin, lipopolysaccharide, Glutathione (GSH), nitroblue tetrazolium (NBT) and Griess reagents were purchased from Sigma-Aldrich (USA). 
Riboflavin, Butylated hydroxyl toluene (BHT) and thiobarbituric acid (TBA) were obtained from Merck (Darmstadt, Germany). The assay kits for serum glutamate oxaloacetate transaminase (SGOT), serum glutamate pyruvate transaminase (SGPT), alkaline phosphatase (ALP), urea, total bilirubin, creatinine and fasting blood sugar (FBS) were purchased from Robonik India Pvt. Ltd., (Mumbai, India). All other chemicals and solvents of analytical grades were purchased from Sisco research Laboratories (Mumbai, India).

\section{Experimental animals}

Adult male albino mice, weighing 25-30 g housed in individual stainless steel cages, were maintained on standard pellet diet with ad libitum water. The animals were maintained under $12 \mathrm{~h}$ light-dark cycle. The animals were used after an acclimatization period of three days in the laboratory animal house. Animal experiments were carried out taking appropriate measures to minimize pain/discomfort in accordance with the guidelines of NIH (USA) regarding the care and use of animals for experimental procedures and with due clearance from Animal Ethics Committee CPCSEA (Ref: NCP/IAEC/CL/101/05/2012-13).

\section{Experimental design}

Animals were fasted for $12 \mathrm{~h}$ and then divided into five groups (6 Animals/group) as mentioned below.

Group A: Normal control

Group B: Positive control (LPS- $3 \mathrm{mg} / \mathrm{kg}$ b.w)

Group C: Curcumin $20 \mathrm{mg} / \mathrm{kg}$ b.w

Group D: Capsaicin $4 \mathrm{mg} / \mathrm{kg}$ b.w

Group E: Combined curcumin and capsaicin (curcumin-10 mg/kg +

capsaicin-2 mg/kg b.w.)

Curcumin and capsaicin were dissolved in olive oil and administered orally for 7 days at respective doses. On the $7^{\text {th }}$ day after $6 \mathrm{~h}$ of oral administration of curcumin, capsaicin and their combination (all the experimental samples), a single intraperitoneal injection of LPS (3 mg/ $\mathrm{kg}$ b.w) in PBS was administered to all the groups except normal/negative control. At the end of the experiment, all the animals were subjected to fasting for $6 \mathrm{hrs}$ and later sacrificed under mild anaesthesia.

\section{Collection and sampling of blood for marker enzymes analysis}

Blood samples were collected and centrifuged immediately at $4000 \mathrm{rpm}$ in cold $\left(4^{\circ} \mathrm{C}\right)$ for $10 \mathrm{~min}$. serum was collected and subjected for biochemical analysis.

\section{Preparation of tissues homogenate}

The liver and kidney were washed and homogenized at 10\% (w/v) using $0.15 \mathrm{M} \mathrm{KCl}$ and centrifuged at $8000 \mathrm{rpm}$ for $10 \mathrm{~min}$. to remove cellular debris. The supernatant was stored at $-20^{\circ} \mathrm{C}$ for further analysis.

\section{Estimation of Lipid peroxidation (LPO)}

The malondialdehyde (MDA) content, a measure of lipid peroxidation was assayed in the form of thiobarbituric acid reactive substances (TBARS) according to the method of Berton et al, (1998). ${ }^{26}$

\section{Estimation of Superoxide dismutase (SOD) activity}

To determine the SOD activity, the riboflavin-NBT assay was adapted with slight modification. ${ }^{27}$ The tissues homogenate $(0.1 \mathrm{ml})$ was mixed with $0.1 \mathrm{ml}$ of $67 \mathrm{mM}$ phosphate buffer $(\mathrm{pH} 7.8)$ containing $0.01 \mathrm{M}$ EDTA and $0.1 \mathrm{~mL}$ of $1.5 \mathrm{mM}$ NBT. Then, $3 \mathrm{~mL}$ of $1.2 \mathrm{mM}$ riboflavin was added followed by incubation at $37^{\circ} \mathrm{C}$ for $5 \mathrm{~min}$. The reaction mixture was exposed to light $(25 \mathrm{~W})$ for $15 \mathrm{~min}$. The inhibition of NBT reduction was determined by measuring the absorbance at $560 \mathrm{~nm}$. Unit of SOD activity was expressed as the amount of enzyme required to inhibit the reduction of NBT using the formula

$$
\text { SOD activity }=\frac{\text { Decrease in } \mathrm{OD} \times 2}{(\mathrm{~S}-\mathrm{B})}
$$

Where, Decrease in OD $=(\mathrm{S}-\mathrm{B})-(\mathrm{T}-\mathrm{C}), \mathrm{S}=$ Absorbance of standard, $\mathrm{B}=$ Absorbance of blank, $\mathrm{T}=$ Absorbance of test and $\mathrm{C}=$ Absorbance of control.

The specific activity was expressed in terms of $\mathrm{U} / \mathrm{mg}$ of protein.

\section{Estimation of catalase (CAT) activity}

Catalase activity was estimated by following the procedure of Aebi. $(1984){ }^{28}$

\section{Estimation of Glutathione S-Transferase (GST) activity}

GST activity was estimated according to the method of Warholm et al. (1985). ${ }^{29}$

\section{Estimation of Nitric oxide (NO)}

Estimation of NO was carried out according to the method of Lee et al. (2006). ${ }^{30}$

\section{Histological analysis}

Liver, lung, heart and kidneys were removed and fixed in neutralized $4 \%$ paraformaldehyde, embedded in paraffin, and sectioned at $6 \mu \mathrm{m}$ thickness and were stained with hematoxylin-eosin. Histopathological changes were evaluated under a light microscope.

\section{Statistical Analysis}

All the experiments were performed in triplicate and statistical analysis was performed using one way ANOVA followed by Dunnett's multiple comparison tests. Data was computed for statistical analysis by using GraphPad prism 5 (San Deigo, CA). The values of $p<0.05, p<0.01$ and $p<0.001$ were considered as statistically significant.

\section{RESULTS}

Effect of curcumin, capsaicin and their combination on serum nonspecific marker enzymes

Administration of LPS to the positive control group showed marked elevation in the level of serum SGOT, SGPT, ALP, total bilirubin (for liver injury), urea, creatinine, (for renal dysfunction) and sugar. Curcumin, capsaicin and their combination revealed significant decrease in the LPS-induced elevation of serum enzymes and molecules. The fold decrease was found to be $1.26,1.3,1.61,2.44,1.10,1.28$ and 1.20 in curcumin treated group; while 1.18, 1.35, 1.52, 2.20, 1.11, 1.11 and 1.30 in capsaicin treated group; 1.94, 1.44, 1.78, 2.70, 1.22, 1.34 and 1.46 in combined curcumin and capsaicin treated group respectively (Table 1). Administration of curcumin and capsaicin ameliorated LPS-induced organ damage thereby decreasing the levels of serum enzymes. Nevertheless, combined curcumin and capsaicin has shown higher protective effect than individual molecules.

\section{Effect of curcumin, capsaicin and their combination on renal and hepatic LPO and NO}

Administration of LPS results in the significant elevation of LPO and NO in kidney and liver of mice and the fold increase was found to be 1.65 and 1.40 for LPO and 1.45 and 2.10 for NO respectively. However, curcumin, capsaicin and their combination has significantly decreased the LPO and NO in both kidney and liver. The fold decrease in LPO of liver and kidney was found to be $2.04 \& 1.25$ and $1.21 \& 1.33$ for NO in curcumin treated group; $1.80 \& 1.15$ for LPO and 1.54 and 1.06 for NO in capsaicin treated group and 2.33 \& 1.53 for LPO and 2.16 \& 1.46 fold in combined curcumin and capsaicin treated group respectively (Figure 1 and 2). 
Thriveni et al:: In vivo protective effect of curcumin and capsaicin against inflammation

Table 1: Effect of curcumin, capsaicin and their combination on serum non-specific marker enzymes in LPS-induced mice.

\begin{tabular}{|c|c|c|c|c|c|}
\hline \multirow{2}{*}{$\begin{array}{c}\text { Serum } \\
\text { non-specific } \\
\text { enzymes }\end{array}$} & \multicolumn{5}{|c|}{ Treated groups } \\
\hline & Normal Control & Positive control & Curcumin & Capsaicin & Cur +cap \\
\hline $\begin{array}{l}\text { SGOT } \\
\text { (IU/L) }\end{array}$ & $88.1 \pm 2.82^{* * *}$ & $180.4 \pm 3.79$ & $144.2 \pm 3.30^{* * *}$ & $153.4 \pm 1.84^{\star *}$ & $96.1 \pm 1.39^{* * *}$ \\
\hline $\begin{array}{l}\text { SGPT } \\
(\mathrm{IU} / \mathrm{L})\end{array}$ & $80.16 \pm 2.20^{\star *}$ & $132.0 \pm 3.14$ & $103.5 \pm 2.42^{\star *}$ & $100.1 \pm 3.98^{\star}$ & $93.9 \pm 1.83^{* *}$ \\
\hline $\begin{array}{c}\text { ALP } \\
(\mathrm{IU} / \mathrm{L})\end{array}$ & $171.6 \pm 1.6^{* * *}$ & $321.1 \pm 3.88$ & $198.6 \pm 1.29^{\star \star}$ & $210.4 \pm 2.09^{\star}$ & $179.8 \pm 2.05^{\star * *}$ \\
\hline $\begin{array}{c}\mathrm{TB} \\
(\mathrm{mg} / \mathrm{dl})\end{array}$ & $0.70 \pm 0.14^{* * *}$ & $2.30 \pm 1.23$ & $0.93 \pm 0.02^{* *}$ & $1.03 \pm 0.3^{* *}$ & $0.84 \pm 0.03^{* * *}$ \\
\hline Urea $(\mathrm{mg} / \mathrm{dl})$ & $68 \pm 1.30^{* * *}$ & $85.5 \pm 2.68$ & $77.1 \pm 1.29^{* *}$ & $77.2 \pm 0.2^{* *}$ & $70.1 \pm 1.34^{* * *}$ \\
\hline Creatinine (mg/dl) & $0.38 \pm 2.43^{* *}$ & $0.51 \pm 2.03$ & $0.40 \pm 1.93^{* * *}$ & $0.46 \pm 3.40^{\star *}$ & $0.38 \pm 0.56^{* * *}$ \\
\hline $\begin{array}{c}\text { FBS } \\
(\mathrm{mg} / \mathrm{dl})\end{array}$ & $49.9 \pm 2.31^{* * *}$ & $95.7 \pm 0.32$ & $79.6 \pm 2.50^{* * *}$ & $75.2 \pm 1.65^{\star *}$ & $65.5 \pm 0.12^{* * *}$ \\
\hline
\end{tabular}

Values are expressed as Mean $\pm \operatorname{SEM}(\mathrm{n}=6)$. One-way ANOVA was performed followed by Dunnett's multiple comparison tests. Significant difference, ${ }^{*} p<0.05,{ }^{* *} p<0.01$ and ${ }^{* * *} p<0.001$.

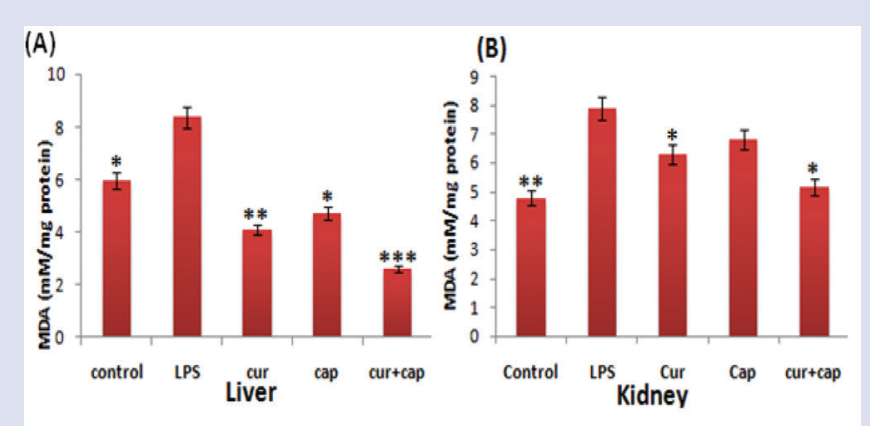

Figure 1: Effect of curcumin, capsaicin and their combination on lipid peroxidation in the (A) Liver and (B) Kidneys of LPS-induced mice. Values are expressed as Mean \pm SEM $(n=6)$. One-way ANOVA was performed followed by Dunnett's multiple comparison tests. Significant difference ${ }^{*} p<0.05,{ }^{* *} p<0.01$ and ${ }^{* * *} p<0.001$.

\section{Effect of curcumin, capsaicin and their combination on antioxidant enzymes CAT, SOD and GST}

The antioxidant enzymes CAT, SOD and GST were decreased prominently up to $2.28,3.38$ and 1.5 fold in liver while in kidneys $3.11,1.15$ and 1.7 fold. However, administration of curcumin, capsaicin and their combination shows significant increase in antioxidant enzymes in liver and kidneys. The fold increase in CAT, SOD and GST in liver were 1.52, 3.46 and 1.29 respectively for curcumin; $1.22,3.15$ and 1.22 for capsaicin and 1.82, 2.96 and 1.53 for combined curcumin and capsaicin. In kidney, the fold increase was 2.79, 1.27 and 1.34 for curcumin; 1.67, 1.15 and 1.11 for capsaicin and 3.48, 1.02 and 1.49 for combined curcumin and capsaicin (Table 2) respectively.

\section{Histopathological analysis}

Liver, kidneys, heart and lung histopathology was done to determine the protective effects of curcumin, capsaicin and their combination on LPS-induced organ injury. The liver, kidneys, heart and lung sections from control group showed normal structural integrity (Figure 3). LPSadministration caused extensive damage to liver in the form of tissue necrosis, kupffer cell hyperplasia, disorganized hepatic architecture;

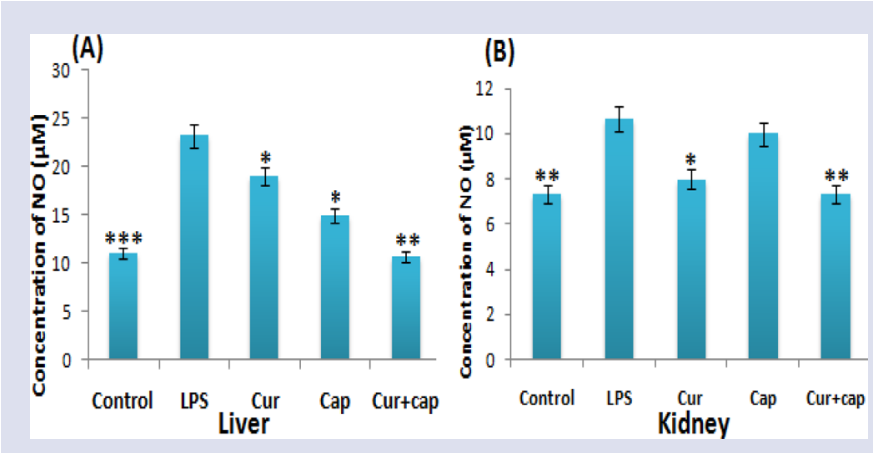

Figure 2: Effect of curcumin, capsaicin and their combination on NO release in the (A) Liver and (B) Kidneys of LPS-induced mice.

Values are expressed as Mean \pm SEM $(n=6)$. One-way ANOVA was performed followed by Dunnett's multiple comparison tests. Significant difference ${ }^{*} p<0.05,{ }^{* *} p<0.01$ and ${ }^{* * *} p<0.001$.

kidneys in the form of segmented sclerosis, bulged nephrons and hyaline atherosclerosis; heart in the form of coagulative necrosis, hemorrhages and inflammatory cells infiltration and lung in the form of injury to cells and inflammatory macrophage infiltration. Organ sections from curcumin and capsaicin groups resulted in the reduction of tissue necrosis, hepatic damage and sclerosis. However, combined curcumin and capsaicin markedly ameliorated the LPS-induced pathological changes and maintained the normal histology (Figure 3).

\section{DISCUSSION}

LPS stimulates immune response, leading to the activation of cascade of immune activities results in tissue damage, multiple organ failure and death. ${ }^{31}$ In the present study, a series of biochemical examinations to distinguish the anti-inflammatory potency of curcumin, capsaicin and their combination on LPS-challenged mice was performed.

The serum non-specific enzymes are potential indicators for the clinical diagnosis of tissues/organs damage during disease condition. LPS intoxication in the body activates cascade of immune responses results in the disruption of structural integrity of the organs and results in the leak- 
Thriveni et al:: In vivo protective effect of curcumin and capsaicin against inflammation

Table 2: Effect of curcumin, capsaicin and their combination on antioxidant enzymes in LPS-induced septic shock in mice.

\begin{tabular}{|c|c|c|c|c|c|c|}
\hline \multirow[t]{2}{*}{ Enzymes } & \multirow[t]{2}{*}{ Tissues } & \multicolumn{5}{|c|}{ Treated groups } \\
\hline & & Normal control & Positive control & $\begin{array}{c}\text { Curcumin } \\
(20 \mathrm{mg} / \mathrm{kg} \mathrm{b.w})\end{array}$ & $\begin{array}{c}\text { Capsaicin } \\
\text { (4 mg/kg b.w) }\end{array}$ & $\begin{array}{c}\text { Cur +Cap } \\
(10 \mathrm{mg} / \mathrm{kg}+2 \mathrm{mg} / \mathrm{kg} \text { b.w })\end{array}$ \\
\hline Catalase & Kidney & $1.34 \pm 0.25^{\star *}$ & $0.43 \pm 0.005$ & $1.20 \pm 0.05^{\star *}$ & $0.72 \pm 0.34$ & $1.50 \pm 0.05^{* *}$ \\
\hline SOD & Liver & $13.23 \pm 0.34^{\star * *}$ & $3.92 \pm 0.22$ & $12.35 \pm 0.15^{\star * *}$ & $11.58 \pm 0.32^{\star * \star}$ & $13.56 \pm 0.29^{* * *}$ \\
\hline GST & Kidney & $10.51 \pm 0.14^{* * *}$ & $6.01 \pm 0.04$ & $8.074 \pm 1.17^{* *}$ & $6.71 \pm 0.19$ & $9.0 \pm 0.34^{* * *}$ \\
\hline
\end{tabular}

Values are expressed as Mean \pm SEM $(n=6)$. One-way ANOVA was performed followed by Dunnett's multiple comparison tests. Significant difference ${ }^{*} p<0.05$, ${ }^{* *} p<0.01$ and ${ }^{* * *} p<0.001$.

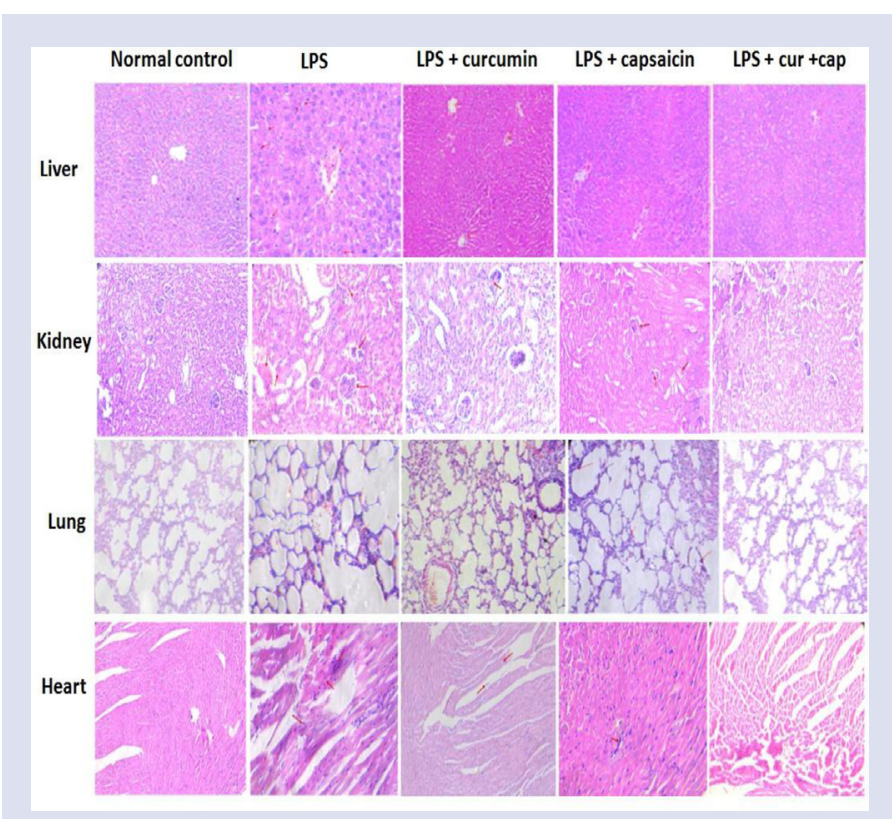

Figure 3: Effect of curcumin, capsaicin and their combination on the tissue damage of liver, kidney, lung and heart in LPS-challenged mice. Male albino mice were administered with curcumin (20 mg/kg b.w), capsaicin ( $4 \mathrm{mg} / \mathrm{kg}$ b.w) and their combination ( $10 \mathrm{mg} / \mathrm{kg}+2 \mathrm{mg} / \mathrm{kg}$ b.w) for 7 days before LPS injection ( $3 \mathrm{mg} / \mathrm{kg}$ ). Histology of liver, kidney, lung and heart tissue sections from the indicated group. The damage sites and infiltration of inflammatory cells are indicated by arrows.

age of enzymes like SGOT, SGPT, ALP, total bilirubin (liver injury), urea creatinine, (renal dysfunction), sugar, cholesterol and triglycerides (heart injury) into the blood. LPS-induced oxidative stress markedly increased the serum non-specific marker enzymes level. Administration of curcumin and capsaicin significantly reduced the LPS-induced tissue injury thereby releasing serum marker enzymes. These results are in agreement with the previous reports. ${ }^{32,33}$ However, mice treated with combined curcumin and capsaicin shows significant reduction in the levels of serum marker enzymes and the effect was found to be more when compared with individual curcumin and capsaicin

Activities of renal and hepatic antioxidant enzymes - catalase, SOD and GST were significantly decreased after LPS treatment. ${ }^{34}$ Whereas, increased activities of antioxidant enzymes by curcumin and capsaicin has been reported in vivo. ${ }^{35}$ In this case, animals treated with curcumin, capsaicin and their combination increased the antioxidant enzymes.
However, the beneficial effect in combined treatment was significant when compared with individuals. LPS treatment induced higher LPO causing oxidative damage to cell membrane and cell death. Hence the LPO is a key marker to analyze the induced oxidative stress in animals. ${ }^{35,36}$ LPS significantly elevated the LPO, whereas, pretreatment with curcumin and capsaicin prevented the LPO in the liver and kidneys of LPS treated mice (Figure 1). However, protective effect of combined curcumin and capsaicin was found to be more than individual molecules corroborating the earlier report. ${ }^{25}$

NO produced during the conversion of arginine into citrulline by nitric oxide synthase in the normal metabolism. LPS treatment elevated NO, as analyzed in renal and hepatic tissues by quantifying nitrite. ${ }^{37,38} \mathrm{NO}$ has been a major factor involved in the pathologic vasodilation, tissue damage and a marker in septic shock. ${ }^{39}$ Curcumin, capsaicin and their combination decreased LPS-induced NO production in liver and kidneys, and the fold decrease being even higher in combined molecules (Figure 2).

Histopathology of vital organs such as liver, kidneys, lung and heart of treated groups mitigated the LPS-induced damage by inhibiting the infiltration of inflammatory cells and significantly decreased the tissues injury. However, combined spice principles have shown effective prevention of LPS-induced organ damage than individuals and in correlation with the serum marker enzymes.

\section{CONCLUSION}

The present findings showed that dietary spice principles curcumin and capsaicin were effective in reducing the oxidant stress in liver and kidneys. Although individual curcumin and capsaicin controlled LPS induced inflammatory response in mice, however combined curcumin and capsaicin had shown additive effect.

\section{REFERENCES}

1. Balzan S, De Almeida Quadros C, De Cleva R, Zilberstein B, Cecconello I. Bacterial translocation: overview of mechanisms and clinical impact. J Gastroenterol Hepatol. 2007;22:464-71.

2. Iskit $A B$, Guc $O$. Effects of endothelin and nitric oxide on organ injury, mesenteric ischemia, and survival in experimental models of septic shock. Acta Pharmacol Sin. 2003;24:953-7.

3. Liu A, Wang W, Fang $H$, Yang $Y$, Jiang $X$, Liu $S$, Hu J, et al. Baicalein protects against polymicrobial sepsis-induced liver injury via inhibition of inflammation and apoptosis in mice. Eur J Pharmacol. 2015;748:45-53

4. Riedemann NC, Guo RF, Ward PA. Novel strategies for the treatment of sepsis. Nat Med. 2003;9:517-24.

5. De Backer D, Orbegozo CD, Donadello K, Vincent JL. Pathophysiology of microcirculatory dysfunction and the pathogenesis of septic shock. Virulence. 2014;5:73-9.

6. Iskander KN, Osuchowski MF, Stearns-Kurosawa DJ, Kurosawa S, Stepien D, 
et al. Sepsis: multiple abnormalities, heterogeneous responses, and evolving understanding. Physiol Rev. 2013;93:1247-88.

7. De Jong HK, Van der Poll T, Wiersinga WJ. The systemic pro-inflammatory response in sepsis. J Innate Immun. 2010;2:422-430.

8. Beutler B, Rietschel ET. Innate immune sensing and its roots: the story of endotoxin. Nat Rev Immunol. 2003;3:169-76.

9. Riedemann NC, Guo RF, Ward PA. The enigma of sepsis. J Clin Invest. 2003;112:460-7.

10. Bereswill S, Mun oz M, Fischer A, Plickert R, Haag LM, et al. Anti-inflammatory effects of resveratrol, curcumin and simvastatin in acute small intestinal inflammation. PLoS ONE. 2010;5:e15099.

11. Biswas SK, McClure D, Jimenez LA, Megson IL, Rahman I. Curcumin induces glutathione biosynthesis and inhibits NF-kB activation and interleukin-8 release in alveolar epithelial cells: mechanism of free radical scavenging activity. Antioxid Redox Signal. 2005;7:32-41.

12. Kunnumakkara AB, Anand P, Aggarwal BB. Curcumin inhibits proliferation, invasion, angiogenesis and metastasis of different cancers through interaction with multiple cell signaling proteins. Cancer Lett. 2008;269:199-225.

13. Sahin K, Orhan C, Tuzcu Z, Tuzcu M, Sahin N. Curcumin ameloriates heat stress via inhibition of oxidative stress and modulation of $\mathrm{Nrf} / \mathrm{HO}-1$ pathway in quail. Food Chem Toxicol. 2012;50:4035-41.

14. Molina-Jijon E, Tapia E, Zazueta C, El Hafidi M, Zatarain-Barron ZL, et al. Curcumin prevents $\mathrm{Cr}(\mathrm{VI})$-induced renal oxidant damage by a mitochondrial pathway. Free Radic Biol Med. 2011;51:1543-57.

15. Waseem M, Parvez S. Mitochondrial dysfunction mediated cisplatin induced toxicity: modulatory role of curcumin. Food Chem Toxicol. 2013;53:334-42.

16. Sood PK, Nahar U, Nehru B. Curcumin attenuates aluminum-induced oxidative stress and mitochondrial dysfunction in rat brain. Neurotox Res. 2011;20:351-61.

17. Joe B, Lokesh BR. Role of capsaicin, curcumin and dietary n-3 fatty acids in lowering the generation of reactive oxygen species in rat peritoneal macrophages. Biochim Biophys Acta.1994;2:255-63.

18. Kim CS, Kawada T, Kim BS, Han IS, Choe SY, et al. Capsaicin exhibits anti-inflammatory property by inhibiting IkB-a degradation in LPS-stimulated peritoneal macrophages.Cell Signal. 2003;3:299-306.

19. Pegorini S, Braida D, Verzoni C, Guerini-Rocco C, Consalez GG, et al. Capsaicin exhibits neuroprotective effects in a model of transient global cerebral ischemia in Mongolian gerbils. British Journal of Pharmacology. 2005; 144:727-35

20. Shimeda $Y$, Hirotani $Y$, Akimoto $Y$, Shindou $K$, ljiri $Y$, et al. Protective effects of capsaicin against cisplatin-induced nephrotoxicity in rats. Biol Pharm Bull. 2005;9:1635-8

21. Sung HJ, Hyung JK, Gi-Su Oh, AiHua Shen, Subin Lee, et al. Capsaicin Ameliorates Cisplatin-Induced Renal Injury through Induction of Heme Oxygenase-1. Mol Cells. 2014;37:234-40.

22. Demirbilek S, Ersoy MO, Demirbilek S, Karaman A, Gurbuz N, et al. Small-dose capsaicin reduces systemic inflammatory responses in septic rats. Anesth
Analg.2004;99:1501-7.

23. Kempaiah RK, Srinivasan K. Influence of dietary curcumin capsaicin and garlic on the antioxidant status of red blood cells and liver in high fat fed rats. Ann Nutr Metab. 2004;48:314-20.

24. Manjunatha $H$, Srinivasan K. Hypolipidemic and antioxidant effects of dietary curcumin and capsaicin in induced hypercholesterolemic rats. Lipids. 2007:42:1133-42.

25. Manjunatha $H$, Srinivasan K. Protective effect of dietary curcumin and capsaicin on induced oxidation of low-density lipoprotein, iron induced hepatotoxicity and carrageenan- induced inflammation. FEBS Journal. 2006;273:4528-37.

26. Berton TR, Conti CJ, Mitchell DL, Aldaz CM, Lubet RA, Fischer SM. The effect of vitamin $\mathrm{E}$ acetate on ultraviolet-induced mouse skin carcinogenesis. Mol Carcinogen. 1998;23:175-84

27. Babitha MP, Bhat SG, Prakash HS, Shetty HS. Differential induction of superoxide dismutase in downy mildew-resistant and susceptible genotypes of pearl millet. Plant Pathol. 2002;51:480-6.

28. Aebi H. Catalase in vitro. In: Packer L, editor. Methods in Enzymology. San Diego: Academic Press.1984;121-6.

29. Warholm M, Guthenberg C, Christer von Bahr, Mannervik B. Glutathione transferases from human liver: Methods of enzymology, Alton Melster (Academic press).1985;500.

30. Lee C, Peng Y, Cheng WH, Cheng HY, Lai FNMT, Chiu TH. Hepatoprotective effect of Phyllanthus in Taiwan on acute liver damage induced by carbon tetrachloride. Am J Chin Med. 2006;34:471-82.

31. Jonathan Cohen. The immunopathogenesis of sepsis. Nature. 2002:420:88591.

32. Sang SY, Sung PK, MiYK, Seok HN. Inhibitory effect of curcumin on liver injury in a murine model of endotoxemic shock. Biotechnol Lett. 2010;32:209-14.

33. Omar ME, Abdel-Salam, Rehab FAR, Amany AS, Abdel RF. Modulation of lipopolysaccharide-induced oxidative stress by capsaicin. Inflammopharmacol. 2012;20:207-17

34. Youcef Necib, Ahlem Bahi. Anti-inflammatory activity of lectin purified from morus nigra against lipopolysaccharide (LPS) induced renal stress in rats WJPR. 2016;5:568-81

35. Mylonas C, Kouretas D. Lipid peroxidation and tissue damage. In Vivo.1999;13:295-309.

36. Marisa Repetto, Jimena SR, Alberto Boveris. Lipid Peroxidation: Chemical Mechanism, Biological Implications and Analytical Determination;2012[chapter 1]

37. Goligorski, S. Gross. Nitric Oxide and the Kidney. Physiology and Pathophysiology: NO in septic shock. New York;1997.

38. Ceppi ED, Smith FS, Titheradge MA. Nitric oxide, sepsis and liver metabolism. Biochem Soc Trans. 1997;25:929-34.

39. Knowles RG, Moncada S. Nitric oxide as a signal in blood vessels. Trends Biochem Sci. 1992;17:399-402.

\section{ABOUT AUTHORS}

Thriveni V: Ph.D. Scholar, Department of Biotechnology, Kuvempu University, Shankaraghatta, Shimoga, Karnataka, India.

Dr. Manjunatha H: Assistant Professor, Department of Biotechnology, Kuvempu University, Shankaraghatta, Shimoga, Karnataka, India.

Dr. Prabhakar BT: Assistant Professor, Postgraduate Department of Studies and Research in Biotechnology, Sahyadri Science College, Kuvempu University, Shimoga, Karnataka, India.

\section{SUMMARY}

- Sepsis is a major worldwide, life threatening and a leading cause of death in intensive care units (ICU). Hyperactivation of the inflammatory response is a remarkable feature of sepsis, initiated at any site vastly by any kind of microbes and/or their products leading to multiple organ damage/dysfunction syndrome (MODS) and death mediated by involvement of multiple pathways. Available Non-steroidal anti-inflammatory drugs (NSAID) although effective at various stages of pathogenicity, pose adverse pathological consequences. The current study unravels anti-inflammatory potency of combined spice principles curcumin and capsaicin against lipopolysaccharide (LPS) induced organ damage in mice model. Curcumin and capsaicin had shown significant restoration of non-specific serum marker enzymes, antioxidant enzymes and attenuated inflammatory cells infiltration thereby preventing tissue/organ damage in LPSchallenged mice. However, the protective effect was found to be more when the two compounds were fed in combination. This beneficial potency of combined spice treatment is may be due to the contribution of diversified active moieties of curcumin and capsaicin in combination compared to individual molecules.

Cite this article: Thriveni V, Manjunatha H, Prabhakar BT. Protective Effect of Dietary Curcumin and Capsaicin on LPS-Induced Inflammation in Mice. Pharmacog J. 2018;10(4):725-9. 